Report

\title{
Finite proliferative lifespan in vitro of a human breast cancer cell strain isolated from a metastatic lymph node
}

\author{
Michael L. Mahacek, ${ }^{1}$ David G. Beer, ${ }^{3}$ Thomas S. Frank ${ }^{2}$ and Stephen P. Ethier ${ }^{1}$ \\ ${ }^{1}$ Department of Radiation Oncology, Division of Cancer Biology, ${ }^{2}$ Department of Pathology, and \\ ${ }^{3}$ Department of Surgery, The University of Michigan Medical Center, 1331 E. Ann St., Ann Arbor, \\ MI 48109-0582, USA
}

Key words: human breast cancer, immortalization, in vitro growth

\section{Summary}

We recently described culture conditions that allow proliferation of metastatic human breast cancer cells from biopsy specimens of certain patient samples. These conditions resulted in the development of an immortalized cell strain designated SUM-44PE. These same culture conditions were used to isolate a human breast cancer cell strain from a metastatic lymph node of a separate breast cancer patient. The SUM-16LN human breast cancer cells isolated from this specimen were cultured either in serum-free medium or serum-containing medium supplemented with insulin and hydrocortisone. Unlike the SUM-44PE cells that have proliferated in culture continuously for over two years, SUM-16LN cells proliferated in culture for approximately 200 days and underwent 15 to 20 population doublings before undergoing cell senescence. No cells of this strain proliferated beyond passage 8. SUM-16LN cells were keratin-19 positive and had an aneuploid karyotype. These cells overexpressed p53 protein and had an amplified epidermal growth factor (EGF) receptor gene that resulted in high level expression of tyrosine phosphorylated EGF receptor protein. Despite the presence of high levels of tyrosine phosphorylated EGF receptor in these cells, they proliferated in serum-free, EGFfree medium and did not secrete detectable levels of EGF-like mitogenic growth factor. In addition, these cells were potently growth inhibited by all concentrations of exogenous EGF tested and by the neutralizing EGF receptor antibody Mab 425. These results suggest that the high level of tyrosine phosphorylated EGF receptor present in these cells is the direct result of receptor overexpression and not the result of the presence of a simulatory ligand. Thus, SUM-16LN represents a human breast cancer cell strain that exhibited genetic and cellular characteristics of advanced human breast cancer cells. Nevertheless, these cells exhibited a finite proliferative lifespan in culture, suggesting that cellular immortalization is not a phenotype expressed by all human breast cancer cells.

\section{Introduction}

Over the past 15 years many investigators have attempted to define tissue culture conditions that allow the routine isolation and growth of human breast cancer ( $\mathrm{HBC}$ ) cells from patient biopsy specimens [1-6]. Despite these intensive efforts, primary human breast cancer cells remain among the most difficult cells to isolate and grow from primary tissues. One aspect of the growth potential of pri- 
mary HBC cells that may contribute to the technical difficulty in isolating these cells, concerns their intrinsic long term growth potential. Although cellular immortalization is a common phenotype of transformed rodent and human cells [7-9] and of rat mammary carcinoma cells [10], the question of whether this phenotype occurs in all human breast cancer cells remains open. However, Smith et al. [11] provided suggestive evidence that breast cancer cells do not have extensive proliferative potential in culture.

In this report, we describe the isolation and growth of a human breast cancer cell strain (SUM-16LN) isolated from a metastatic lymph node of a breast cancer patient. These cells exhibited cellular and genetic characteristics of human breast cancer cells including an abnormal karyotype, an amplified EGF receptor gene, and overexpression of p53 protein. Despite these important cellular alterations, SUM-16LN cells exhibited a finite proliferative lifespan in vitro. These cells were isolated and serially passaged seven times over approximately 200 days. However, the cells lost proliferative potential during passage 8 and were never subcultureable beyond that point. Thus, human breast cancer cells isolated from a metastatic site and grown over many months in culture do not necessarily yield a truly immortalized cell line. This finding is consistent with the hypothesis that cellular immortalization is not a necessary phenotype of human breast cancer cells.

\section{Materials and methods}

\section{Isolation and culture of SUM-16LN cells}

SUM-16LN cells were isolated by collagenase dissociation of a metastatic lymph node of a patient with a grade 3 infiltrating ductal carcinoma of the breast essentially as described previously for primary tumor tissue $[5,6]$. The isolated cells were seeded at $5 \times 10^{5}$ cells per $60 \mathrm{~mm}$ tissue culture dish and maintained in Ham's F-12 medium supplemented with insulin $(5 \mu \mathrm{g} / \mathrm{ml})$, hydrocortisone $(1 \mu \mathrm{g} / \mathrm{ml}), 5 \%$ fetal bovine serum, and antibiotics ( $5 \%$-IH medium). The cells were kept in primary culture for two months, and epithelial cell colonies were selectively removed from the stromal cell monolayer by incubation of the cells for 15 minutes at room temperature in calcium and magnesiumfree Hanks balanced salt solution containing $10 \mathrm{mM}$ ethylene diamine tetra-acetic acid (EDTA). The cells isolated in this way were reseeded onto $35 \mathrm{~mm}$ culture wells and maintained in secondary culture for an additional two months. Thereafter, the cells were split with a ratio of $1: 3$ using trypsin:EDTA. At passage 2, some of the cells were switched to serum-free medium supplemented with insulin and hydrocortisone (SF-IH medium). In the serum-free medium, serum is replaced with bovine serum albumin $(1 \mathrm{mg} / \mathrm{ml})$, ethanolamine $(5 \mathrm{mM})$, transferrin $(1 \mu \mathrm{g} / \mathrm{ml})$, sodium selenite $(50 \mathrm{ng} / \mathrm{ml})$, and triiodothyronine $(50 \mathrm{ng} / \mathrm{ml})$.

\section{Cell growth assays}

To assess the growth of SUM-16LN cells in serumfree medium in the presence of additional exogenous growth factors, cells were seeded at $10^{5}$ cells per $35 \mathrm{~mm}$ culture dish in SF-IH medium and grown for two weeks in the presence of defined growth factors. After two weeks, the mean number of cells per dish was determined by counting isolated nuclei with a Coulter Counter as previously described $[12,13]$. To test conditioned medium for the presence of EGF-like mitogenic activity, the normal human mammary epithelial cell line MCF-10A was used. MCF-10A cells were seeded at $3.5 \times 10^{4}$ cells per $35 \mathrm{~mm}$ culture well and grown in SF-IH medium in the presence or absence of 48-hour conditioned medium obtained from near confluent cultures of SUM-16LN cells. The SUM-16LN cells used for these experiments were grown for at least two passages in SF-IH medium. MCF-10A cells grown in SF-IH medium supplemented with $10 \mathrm{ng}$ / $\mathrm{ml}$ EGF served as positive controls. After one week in culture, the number of MCF-10A cells per well was determined by counting isolated nuclei. 
Western blot analyses

For preparation of membranes to be used in Western blot experiments, confluent monolayers of cells were scraped in $20 \mathrm{mM}$ HEPES containing $20 \mathrm{mM}$ sodium orthovanadate, $10 \mathrm{mM}$ sodium pyrophosphate, and $1 \mathrm{mM}$ phenylmethyl sulfonyl fluoride (PMSF), dounce homogenized 50 times, and centrifuged at $800 \times \mathrm{g}$ for 10 minutes. The supernatant was then centrifuged at $100,000 \times \mathrm{g}$ for 30 minutes and the pellet resuspended in a lysis buffer consisting of $10 \mathrm{mM}$ phosphate $\mathrm{pH} 7.5,100 \mathrm{mM} \mathrm{NaCl}, 1 \%$ Triton-X 100, $0.5 \%$ sodium deoxycholate, $0.1 \%$ sodium dodecyl sulfate (SDS), $5 \mathrm{mM}$ sodium orthovanadate, and $10 \mathrm{mM}$ sodium pyrophosphate. The lysate was assayed for protein content and then defined amounts of membrane protein were added to individual wells and electrophoresed on a $7.5 \%$ SDS-polyacrylamide gel. Following electrophoresis, the proteins were electroblotted onto Imobilon-P membranes (Millipore Corp., Bedford, MA), blocked with $2 \%$ non-fat dry milk in Tris-buffered saline with $1 \%$ Tween-20. Blots were probed with the EGF receptor antibody Ab-3 (Oncogene Science, Uniondale, NY) or the anti-phosphotyrosine antibody PY-20 (ICN, Cost a Mesa, CA). Protein bands were visualized by incubating blots with biotinylated secondary antibody and then with Vectastain $\mathrm{ABC}$ reagents (Vector Laboratories, Burlingame, CA) using diaminobenzidine as a substrate.

For immunoprecipitation experiments, 5 confluent $60 \mathrm{~mm}$ dishes of SUM-16LN cells were lysed in a buffer consisting of $10 \mathrm{mM}$ Tris $\mathrm{pH} 7.6,1 \%$ Triton-X 100, 5 mM EDTA, $30 \mathrm{mM}$ sodium pyrophosphate, $50 \mathrm{mM}$ sodium fluoride, $100 \mu \mathrm{M}$ sodium orthovanadate, $0.1 \%$ sodium azide, and $1 \mathrm{mM}$ PMSF. The lysate was incubated on ice for 15 minutes and then centrifuged at $14,000 \times \mathrm{g}$ for 15 minutes. The lysate was incubated overnight at $4^{\circ} \mathrm{C}$ with the EGF receptor antibody Ab-1 (Oncogene Science, Uniondale, NY) with agitation. Next, protein-A agarose was added to the lysate and incubated at room temperature for 2 hours. The beads were washed three times by centrifugation at $2000 \times \mathrm{g}$ for 1 minute. The beads were then resuspended in SDSsample buffer, boiled for five minutes, centrifuged, and the eluates loaded onto a 7\% SDS-polyacryla- mide gel, electrophoresed, and blotted as described above.

For Western blot analysis of p53 proteins, whole cell lysates were prepared by scraping cells in a buffer consisting of $10 \mathrm{mM}$ phosphate $\mathrm{pH} 7.5,100 \mathrm{mM}$ $\mathrm{NaCl}, 1 \%$ Triton-X $100,0.5 \%$ sodium deoxycholate, and $0.1 \%$ SDS. The crude lysates were electrophoresed through a $10 \%$ SDS-polyacrylamide gel and Western blots were probed with the p53 antibody Ab-2 (Oncogene Science, Uniondale, NY) and processed as described above. Immunohistochemical detection of $\mathrm{p} 53$ in formalin-fixed, paraffin-embedded tissue sections was performed using PAb1801 (Oncogene Science, Uniondale, NY), a murine monoclonal antibody specific for human p53 and recognizing a denaturation-resistant epitope between amino acids 32 and 79. Pre-heated tissue sections were deparaffinized and incubated with suppressor serum for 10 minutes. After overnight incubation with primary antibody at a 1:1000 dilution, sections were incubated with a 1:200 dilution of biotinylated antimouse IgG for 1 hour followed by successive incubations with $1 \mu \mathrm{g} / \mathrm{ml}$ streptavidin-alkaline phosphatase (BRL Life Technologies, Bethesda, MD) and nitroblue tetrazolium/5-bromo-4chloro-3-indolyl phosphate substrate.

\section{Differential polymerase chain reaction (PCR)}

DNA was isolated from SUM-16LN cells and MCF-10A cells using a modification of the method described by Kovach et al. [14]. Briefly, $10^{4}$ mammary epithelial cells were washed three times by centrifugation with $5 \%$ dextrose in water. The cell pellet was then resuspended in $20 \mu$ of a buffer consisting of $10 \mathrm{mM}$ Tris ( $\mathrm{pH} 8.3$ ), $50 \mathrm{mM} \mathrm{KCl}, 1.5 \mathrm{mM}$ $\mathrm{MgCl}_{2}, 20 \mathrm{mM}$ dithiothreitol, $1.7 \mu \mathrm{M}$ sodium dodecyl sulfate, and $10 \mu \mathrm{g}$ proteinase $\mathrm{K}$. The cells were incubated for 1 hour at $37^{\circ} \mathrm{C}$ and then incubated for an additional 5 minutes at $85^{\circ} \mathrm{C}$. PCR reagents were then added directly to the DNA preparation.

Differential PCR was performed using oligonucleotide primers specific for a $110 \mathrm{bp}$ fragment of the EGF receptor gene corresponding to nucleotides 3901-4010 and a 90 bp fragment of the dopamine receptor D2 gene (DRD2) corresponding to 
nucleotides 1464-1554. In this procedure both sequences are amplified by PCR concurrently and the primers were homologous to the first $20 \mathrm{bp}$ (sense) and last $20 \mathrm{bp}$ (antisense) of each sequence. Reagents and conditions for PCR were from the $\mathrm{Ge}$ neAmp kit (Perkin Elmer Cetus, Norwalk, CT). The PCR mixture contained $10 \mathrm{mM}$ Tris- $\mathrm{HCl}$ (pH 8.3), $50 \mathrm{mM} \mathrm{KCl}, 0.2 \mathrm{mM}$ each dNTP, $0.2 \mu \mathrm{M}$ each oligonucleotide primer, 2.5 units Taq polymerase, $1.5 \mathrm{mM} \mathrm{MgCl}_{2}$, and DNA obtained from $10^{4}$ mammary epithelial cells, or $100 \mathrm{ng}$ of control DNA, in a total volume of $100 \mu$ l. Samples were overlaid with $80 \mu \mathrm{l}$ mineral oil. The PCR proceeded through 40 cycles $\left(1.8 \mathrm{~min}\right.$ at $95^{\circ} \mathrm{C}, 2 \mathrm{~min}$ at $55^{\circ} \mathrm{C}$, and 2 min at $72^{\circ} \mathrm{C}$ ) with an initial cycle of $95^{\circ} \mathrm{C}$ for five minutes and an end cycle of $72^{\circ} \mathrm{C}$ for $10 \mathrm{~min}$ utes. After PCR, $10 \mu 1$ of each sample was electrophoresed on a $12 \%$ polyacrylamide gel and stained with ethidium bromide. The gels were photographed and the band intensities were quantified from photographic negatives by scanning laser densitometry (Molecular Dynamics, Palo Alto, CA). Amplification was determined by comparing the ratio of EGF receptor to DRD2 band intensities between normal mammary epithelial cells and SUM-16LN cells. Positive and negative control cells were obtained from matched samples of normal and neoplastic tissues from patients with lung adenocarcinoma that had been previously screened by
Southern blot hybridization for EGF receptor gene amplification.

\section{Results}

\section{Isolation and growth of SUM-16LN cells}

Recently we described culture conditions that allow selective isolation of human breast cancer cells from metastatic sites of certain patient samples [6]. These culture conditions were used to isolate SUM-16LN cells. SUM-16LN cells were plated at $5 \times 10^{5}$ cells per $60 \mathrm{~mm}$ collagen-coated tissue culture dish and grown in Hams F-12 medium supplemented with insulin, hydrocortisone, and 5\% FBS. Under these conditions, stromal cells grew slowly and formed a confluent lawn of cells that density arrested. Over the first 50 days in primary culture, epithelial cell colonies developed within the lawn of density arrested stromal cells. These colonies were then differentially isolated using $10 \mathrm{mM}$ EDTA in calcium and magnesium Hanks balanced salt solution. Human breast cancer cells isolated in this way were seeded into secondary culture and grown to confluence over the next 60 days. The cells were then subcultured with a split ratio of 1:3 approximately once per month over the next six months. At the beginning of passage 2 , cultures were initiated in serum-free medium. From passages 2 through 8 ,

Table 1. Culture history of SUM-16LN cells

\begin{tabular}{ccccl}
\hline Passage number & Days in passage & Days in culture & Split ratio & Experiments \\
\hline Primary & 51 & 51 & - & - \\
P1 & 61 & 112 & $1: 3$ & - \\
P2 & 127 & $1: 3$ & started cells in serum-free medium \\
P3 & 15 & 139 & $1: 3$ & - \\
P3-SF & 12 & 146 & $1: 3$ & - \\
P4 & 19 & 148 & $1: 3$ & - \\
P4-SF & 9 & 161 & $1: 3$ & tested exogenous EGF \\
P5 & 168 & $1: 3$ & performed Western blot analysis \\
P5-SF & 170 & $1: 3$ & - \\
P6 & 9 & 187 & $1: 3$ & - \\
P6-SF & 19 & 196 & $1: 3$ & cells stopped growing in P7 \\
P7 & 26 & 217 & $1: 3 / 1: 1$ & no cell growth \\
P7-SF & 30 & 226 & $1: 3 / 1: 1$ & \\
P8 & 30 & & & \\
\hline
\end{tabular}


SUM-16LN cells were carried simultaneously in both the serum-containing and the serum-free media. The proliferative history of SUM-16LN cells is given in Table 1.

\section{Characterization of SUM-16LN cells}

As we reported previously, SUM-16LN cells were a keratin-19 positive cell strain with an abnormal karyotype [6]. The modal chromosome number was 62 and the cells exhibited numerous marker chromosomes. To characterize these cells further, a series of Western blot experiments were carried out. SUM-16LN cells grown in the SF-IH medium for two to three passages were used for Western blot experiments. Phosphotyrosine Western blot analysis of membrane protein obtained from SUM-16LN cells indicated the presence of a highly tyrosine phosphorylated protein that migrated at approximately $170 \mathrm{kDa}$ (Fig. 1). The apparent molecular weight of the tyrosine phosphorylated protein was consistent with its identity as the EGF receptor, and Western blot analysis using EGF receptor antibodies confirmed that the two bands co-migrated on the gel. To confirm the identity of the p170 tyrosine phosphorylated protein as the EGF receptor, immunoprecipitation experiments were carried out using EGF receptor antibodies. The immunoprecipitates were electrophoresed and transferred to Immobilon-P membranes, and the Western blots were probed with the phosphotyrosine antibody PY-20. The result of this experiment indicated clearly that the highly tyrosine phosphorylated p170 is the EGF receptor (Fig. 1).

The results of the Western blot experiments suggested that the EGF receptor gene may be amplified in these cells. In SUM-16LN cells, high levels of tyrosine phosphorylated EGF receptor were detected when as little as 5 to $10 \mu \mathrm{g}$ of membrane protein were loaded per lane of the gel. In cells that express single copy levels of EGF receptor protein, such as the normal human mammary epithelial cell line $\mathrm{MCF}-10 \mathrm{~A}, 100 \mu \mathrm{g}$ of membrane protein per lane is required to detect tyrosine phosphoryated EGF receptor following stimulation with EGF [15]. Thus, this finding suggested that the EGF receptor

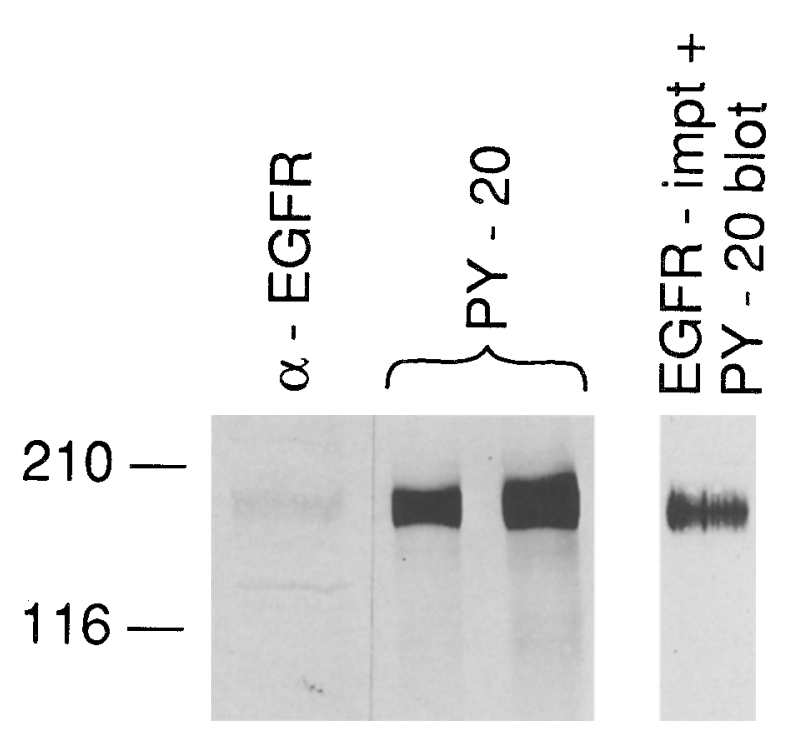

Fig. 1. Western blot analysis of membrane protein and immunoprecipitates obtained from SUM-16LN cells. Membrane protein was obtained from near confluent cultures of SUM-16LN cells and defined amounts of membrane protein were loaded per lane, electrophoresed, blotted, and probed either with a polyclonal EGF receptor antibody or an anti-phosphotyrosine antibody (PY-20). Alternatively, whole cell lysates were immunoprecipitated with an EGF receptor antibody and Western blots were probed with PY-20 antibody. Lane 1,100 $\mu \mathrm{g}$ membrane protein loaded, and blot probed with anti-EGF receptor antibody; Lanes 2 and 3 , five or ten $\mu$ g membrane protein loaded and blot probed with PY-20; Lane 4, EGF receptor immunoprecipitate loaded and blot probed with PY-20.

gene was amplified in these cells. To confirm that the EGF receptor gene was amplified, differential PCR analysis was carried out [16,17]. For these experiments, primers for the human EGF receptor gene and the human DRD2 gene were used. PCR was carried out for 40 cycles and the PCR products were analyzed in an ethidium bromide stained polyacrylamide gel (Fig. 2). The results of this analysis indicated that the ratio of the intensity of the PCR amplified EGF receptor gene to the DRD2 PCR product was 5.2 as compared to a ratio of approximately 1 for control DNA from tissue in which EGF receptor is not amplified. The positive control tumor sample used in this experiment also had an EGF receptor to DRD2 ratio of greater than 5 and has been demonstrated to have a 10 -fold amplification of EGF receptor by Southern blot analysis [18]. Thus, these results are consistent with the Western blot experiments and indicate that EGF receptor is 


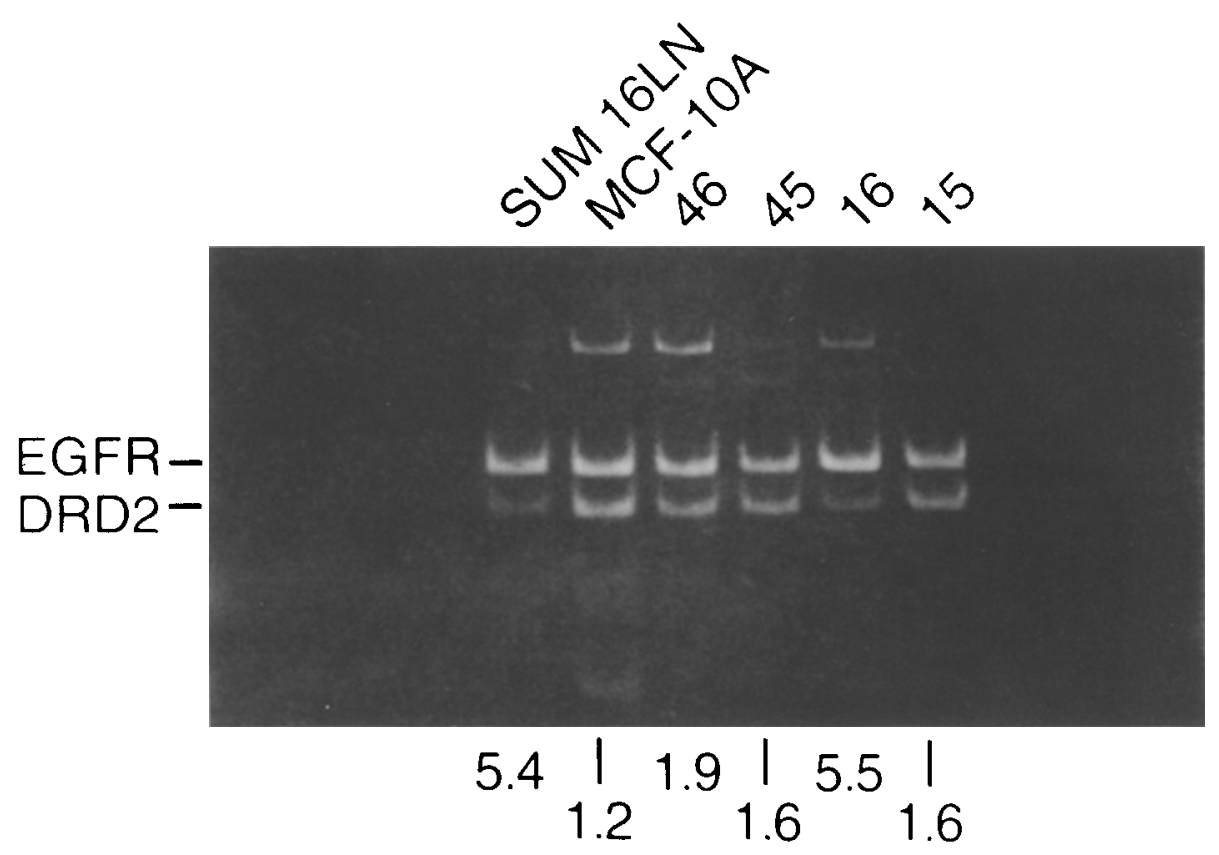

Fig. 2. Differential PCR analysis of SUM-16LN cells and MCF-10A cells. DNA isolated from $10^{4}$ SUM-16LN cells or MCF-10A cells was PCR amplified using primers specific for the EGF receptor gene and the dopamine receptor gene (DRD2). PCR products were visualized by ethidium bromide staining of a polyacrylamide gel. The upper band represents the EGF receptor PCR product and the lower band the DRD2 product. The numbers below the figure represent the ratio of intensity of the upper band to the lower band. Samples 45 and 46 are tumor and normal cells respectively obtained from a patient with esophageal adenocarcinoma and for which Southern blotting indicated no amplification of the EGF receptor gene. Samples 15 and 16 refer to a similar matched pair of tissues from an esophageal adenocarcinoma patient in which Southern blotting revealed a 10 to 15 fold amplification of the EGF receptor gene.

amplified and overexpressed in SUM-16LN cells. Differential PCR analysis was used instead of Southern blot analysis because the number of cells available for the assay was limited.

Since SUM-16LN cells were isolated in medium devoid of exogenous EGF, experiments were carried out to determine if the high level of tyrosine phosphorylated EGF receptor in these cells was the result of the presence of low levels of an EGF-like ligand present in serum or the result of secretion of an EGF-like growth factor. To determine if EGFlike factors present in serum were required for growth of SUM-16LN, cells were tested for their ability to grow in serum-free medium supplemented with insulin and hydrocortisone. In the serumfree media used in our laboratory, serum is replaced with ethanolamine, transferrin, sodium selenite, triiodothyronine, and bovine serum albumin [19]. Table 1 indicates that SUM-16LN cells adapted well to the serum-free medium and grew over 4 passages in this medium. Thus, even in serum-free medium,
SUM-16LN cells did not exhibit any requirement for exogenous EGF for growth. To determine if SUM-16LN cells grown in serum-free medium would exhibit a mitogenic response to exogenous EGF, cells were seeded at low density in the presence of varying concentrations of EGF. The results shown in Fig. 3 indicate that SUM-16LN cells were potently growth inhibited by exogenous EGF. Even concentrations as low as $0.1 \mathrm{ng}$ per $\mathrm{ml}$ had a negative effect on the growth of the cells. In addition, the neutralizing EGF receptor antibody Mab 425 also inhibited growth of these cells (not shown). To determine if SUM-16LN cells were secreting an EGFlike growth factor, serum-free conditioned medium obtained from near-confluent cultures of SUM-16LN cells was tested for its ability to stimulate growth of MCF-10A cells in serum-free, EGFfree medium. We have demonstrated previously that MCF-10A cells do not proliferate in serum-free medium in the absence of EGF, and these cells are sensitive and specific indicators for the presence of 


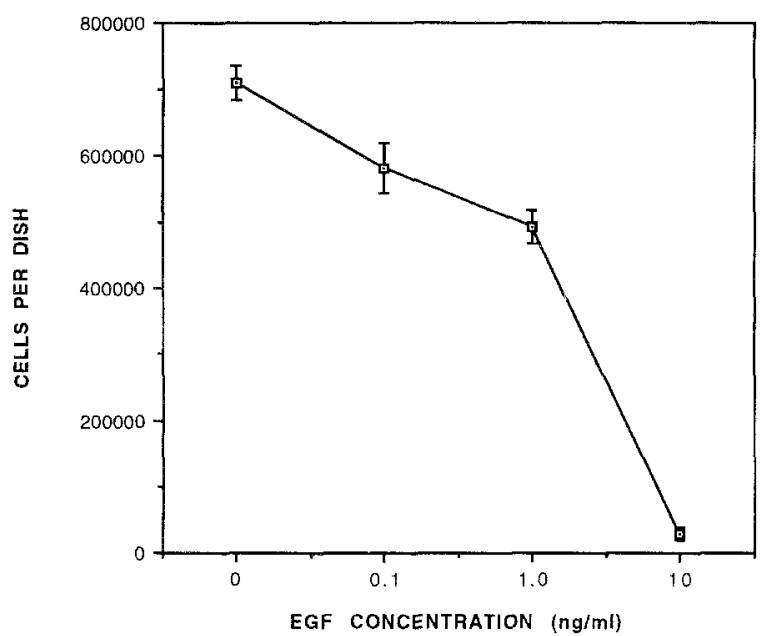

Fig. 3. Growth response of SUM-16LN cells to exogenous EGF. SUM-16LN cells that had been cultured in SF-IH medium for two passages were plated at $10^{5}$ cells per $35 \mathrm{~mm}$ culture well and grown for two weeks in the absence or presence of varying concentrations of EGF. Each point represents the mean number of cells per well in triplicate wells and the error bars indicate the range in the data.

biologically active EGF-like growth factors [15]. The results shown in Fig. 4 indicate the absence of detectable EGF-like mitogenic activity in conditioned medium of SUM-16LN cells. Taken together, these results suggest that the high level of phosphorylated EGF receptor exhibited by SUM-16LN cells is the result of the EGF receptor gene amplification and consequent overexpression of receptor protein and not the result of activation by a stimulatory ligand.

In addition to overexpression of activated EGF receptor, SUM-16LN cells also overexpressed p53 protein. Western blot analysis carried out with lysates obtained with SUM-16LN cells indicated the presence of p53 protein levels similar to that observed with T-47D cells that are known to have a mutant p53 gene (Fig. 5a). Immunohistochemical analysis of the biopsy specimen that yielded this cell strain confirmed this result and indicated positive nuclear staining for p53 in the breast cancer cells in both the primary tumor specimen and the metastatic lymph node (Fig. $5 \mathrm{~b}$ and $5 \mathrm{c}$ ). The nuclear staining pattern of $\mathrm{p} 53$ protein is consistent with the presence of a p53 mutation in these cells. This finding also provides further evidence that the cell strain

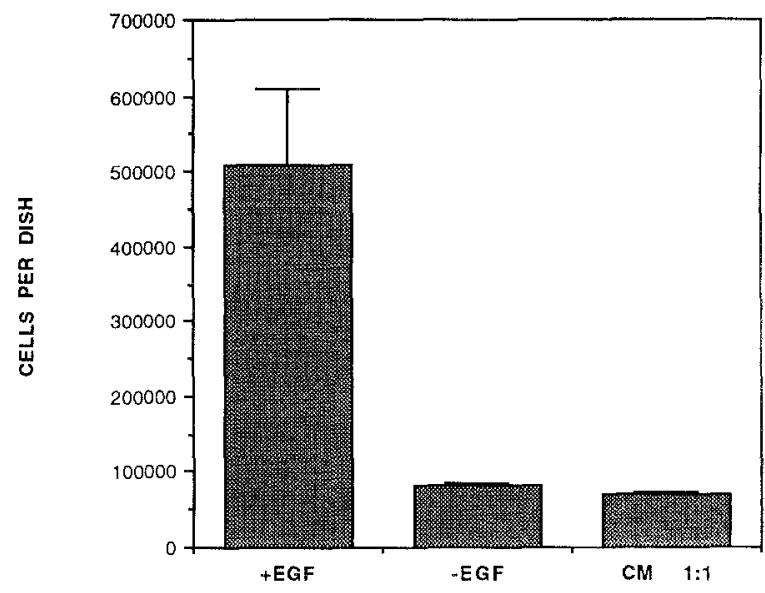

Fig. 4. Analysis of SUM-16LN conditioned medium for EGF like mitogenic activity. MCF-10A cells were plated in $35 \mathrm{~mm}$ culture wells at $10^{4}$ cells per well. The cells were then cultured for one week in SF-IH medium in the presence or absence of EGF or in SF-IH medium plus 48 hour conditioned medium obtained from SUM- $16 \mathrm{LN}$ cells $(50 \% \mathrm{v} / \mathrm{v})$. Bars represent the mean number of cells in triplicate wells and error bars indicate the range in the data.

isolated from this specimen is representative of the breast cancer cells of this patient.

\section{Loss of proliferative potential of SUM-16LN cells}

Table 1 indicates that SUM-16LN cells proliferated continuously in both the serum-containing and serum-free media for approximately 200 days before losing growth potential. The cells then expressed a classic pattern of cellular senescence. Upon subculture to passage 8 the cells abruptly stopped proliferating and underwent morphological changes consistent with cellular senescence. Reinitiating SUM-16LN cultures by thawing frozen ampoules of cells prepared at earlier passage levels or by thawing ampoules of the original cell preparation failed to generate cells that would proliferate beyond passage 8 . In addition, many unsuccessful attempts were made to modify the culture conditions for SUM-16LN cells at earlier passage levels by altering the substratum on which they were grown and by testing their responsiveness to several hormones and growth factors. Thus, these results indicate that SUM-16LN represents a true human breast cancer 


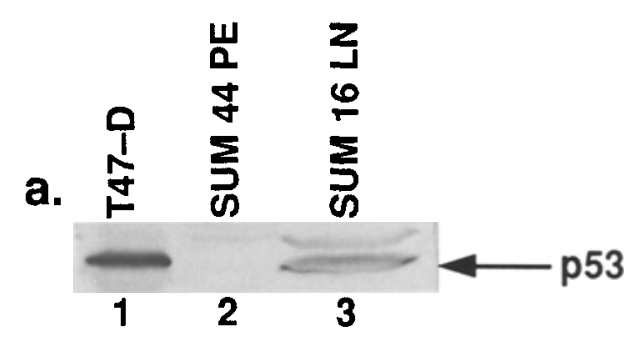

b.

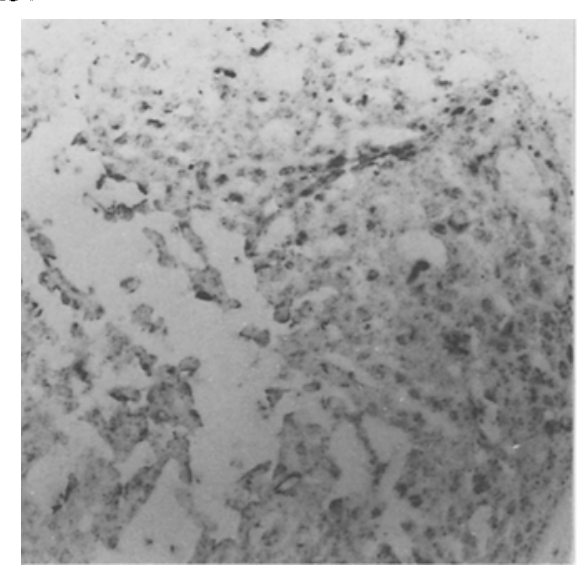

c.

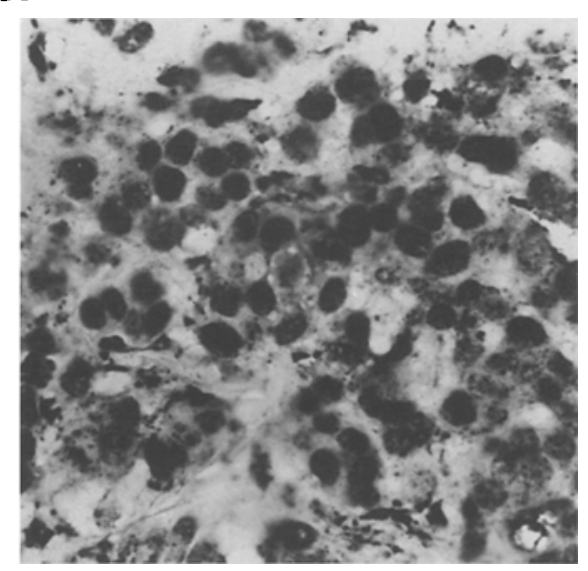

Fig. 5. p53 overexpression in SUM-16LN cells. Panel A, Western blot analysis of cell lysates obtained from T47-D human breast cancer cells (lane 1), SUM-44PE human breast cancer cells (lane 2), and SUM-16LN cells (lane 3). Panels B and C, Immunohistochemical analysis of the primary tumor specimen from which the SUM-16LN strain was derived. Note the absence of p53 nuclear staining in an area of the tumor consisting of intraductal carcinoma (panel B, 20x) and intense nuclear p53 staining of the breast cancer cells in the invasive component of the tumor (panel C, $40 \times$ ).

cell strain that expressed a finite proliferative lifespan in vitro.

\section{Discussion}

It is often difficult to distinguish in absolute terms the difference between a finite proliferative lifespan of cells measured in vitro and the loss of growth potential that results from deficiencies in tissue culture conditions. With regard to human breast cancer cells, this question has been particularly difficult to address due to the inherent difficulty in the isolation and growth of human breast cancer cells from primary tissues. Clearly, some human breast cancer cells are immortalized as a small percentage of human breast cancer specimens yield immortalized cell lines. The frequency with which human breast cancer cell lines have been developed has increased in recent years as tissue culture meth- ods have improved $[3,4,19]$. However, the vast majority of human breast cancer cells obtained from primary or metastatic sites do not yield permanent cell lines. In 1987 Smith et al. [11] suggested that the proliferative lifespan of some human breast cancer cells is indeed quite limited. In those studies, serial pleural effusion specimens were obtained from the same patient over a 2 year period. Cells obtained from the first two specimens did not proliferate in culture but cells from the third sample grew and yielded a long-term breast cancer cell line.

In these report, we extend the observations made earlier by Smith and co-workers [11]. We have developed culture methods that support establishment and proliferation of metastatic human breast cancer cells from some patients. These methods resulted in the isolation and growth of the human breast cancer cell line SUM-44PE [6] and a second cell line designated SUM-52PE that is currently be- 
ing further characterized. These same culture conditions were used to isolate and grow the cell strain SUM-16LN described here. Interestingly, the course of cell growth of SUM-16LN was very similar to that expressed by the SUM-44PE cells in early passages. However, whereas SUM-44PE cells continued to express proliferative potential and are growing nearly two years later, SUM-16LN cells ceased to proliferate and senesced at passage 8 , after approximately 200 days in culture. Although it is difficult to determine precisely, we estimate that SUM-16LN cells underwent 15 to 20 population doublings before losing growth potential. The fact that these cells were isolated and cultured for many months before losing proliferative potential under the same culture conditions that have supported continuous growth of two other cell lines, suggests that SUM-16LN were not immortal but rather had a finite proliferative capacity. However, one can never completely rule out the possibility that deficiencies in culture conditions contributed to the demise of SUM-16LN cells in ways that did not affect other breast cancer cell lines.

SUM-16LN cells exhibited several interesting genetic alterations. First, these cells were aneuploid with a modal chromosome number of 62 and contained several marker chromosomes [6]. In addition, these cells overexpressed $\mathrm{p} 53$ protein and contained an amplified EGF receptor gene that resulted in high level expression of tyrosine phosphorylated EGF receptor even when grown over several passages in serum-free, EGF-free medium, and EGF-like mitogenic activity was not detected in conditioned medium from these cells. These results suggest that overexpression of the receptor protein itself results in high levels of tyrosine phosphorylated receptor in the absence of ligand. The most recent models of activation of EGF receptor tyrosine kinase have proposed that EGF receptors exist in a dynamic equilibrium between monomeric and dimeric states and that the presence of ligand shifts the equilibrium toward the dimeric (kinase active) state $[21,22]$. EGF receptor dimers then undergo tyrosine phosphorylation by an intermolecular mechanism. A corollary of this hypothesis is that all cells have low levels of EGF receptor dimers in the absence of ligand but the levels of kinase active re- ceptors are insufficient to yield a mitogenic signal. If this is correct, then amplification of the receptor may itself result in the presence of sufficient numbers of receptor dimers per cell to yield active mitogenic signaling. Indeed, high levels of tyrosine phosphorylated receptors are a common observation in cells that have amplification of EGF receptor or erbB-2 receptor genes [23, 24].

Although the very high levels of tyrosine phosphorylated EGF receptors in these cells are inconsistent with the presence of very low levels of EGFlike ligand, one cannot completely rule out the possible contribution of a non-secreted growth factor such as incompletely processed TGF- $\alpha$ that could be acting via a juxtacrine mechanism. Unfortunately, the senescence of the SUM-16LN cell strain occurred before sufficient cells could be obtained to carry out a thorough Northern analysis to address this question.

In summary, SUM-16LN cells are a human breast cancer cell strain isolated from a metastatic lymph node of a patient with grade 3 infiltrating ductal carcinoma of the breast. These cells, which have an abnormal karyotype, and overexpress both p53 protein and EGF receptor protein, have a finite proliferative lifespan in vitro and senesced after 15 to 20 population doublings. These results are consistent with the hypothesis that cellular immortalization is not a characteristic of all human breast cancer cells.

\section{Acknowledgements}

The authors gratefully acknowledge Cheryl Dilts for assistance with cell culture and Western blot experiments, Rene Bartos for p53 immunohistochemistry, and Jason Moore for differential PCR experiments. We also acknowledge Drs. David August, Vernon Sondak, Alfred Chang, and the members of The University of Michigan Breast Care Center for their assistance in procuring human breast cancer specimens for the laboratory. This work was supported by NCI grant CA-40064 and by ACS Clinical Oncology Fellowship 91-81 to MLH and by a grant to TSF from the Harris Foundation. 


\section{References}

1. Smith HS, Lan S, Ceriani R, Hackett AJ, Stampfer MR: Clonal proliferation of cultured nonmalignant human breast epithelia. Cancer Res 41: 4637-4643, 1981

2. Petersen OW, van Deurs B: Preservation of defined phenotypic traits in short-term cultured human breast carcinoma derived epithelial cells. Cancer Res 47: 856-866, 1987

3. Band V, Sager R: Distinctive traits of normal and tumor derived human mammary epithelial cells expressed in a medium that supports long-term growth of both cell types. Proc Natl Acad Sci USA 86: 1249-1253, 1989

4. Meltzer P, Leibovitz A, Dalton W, Villar H, Kute T, Davis J, Nagle R, Trent J: Establishment of two new cell lines derived from human breast carcinomas with HER-2/neu amplification. Br J Cancer 63: 727-735, 1991

5. Ethier SP, Summerfelt RM, Cundiff KC, Asch BB: The influence of growth factors on the proliferative potential of normal and primary breast cancer-derived human breast epithelial cells. Breast Cancer Res Treat 17: 221-230, 1990

6. Ethier SP, Mahacek ML, Gullick WJ, Frank TJ, Weber BL: Differential isolation of normal luminal mammary epithelial cells and breast cancer cells from primary and metastatic sites using selective media. Cancer Res 53: 627-635, 1993

7. Hayflick L, Moorhead PS: The serial cultivation of human diploid cell strains. Exp Cell Res 25: 585-621, 1961

8. Newbold RR, Overell RW: Fibroblast immortality is a prerequisite for transformation of EJ c-Ha-ras oncogene. Nature 304: 648-651, 1983

9. Lechner JF, Jaugen A, McClendon IA, Pettis WE: Clonal growth of normal adult human bronchial epithelial cells in a serum-free medium. In Vitro 18: 633-642, 1982

10. Ethier SP, Cundiff KC: Importance of extended growth potential and growth factor independence on in vivo neoplastic potential of primary rat mammary carcinoma cells. Cancer Res 47: 5316-5322, 1987

11. Smith HS, Wolman SR, Dairkee SH, Hancock MC, Lippman M, Leff A, Hackett AJ: Immortalization in culture: Occurrence at a late stage in the progression of breast cancer. $J$ Natl Cancer Inst 78: 611-615, 1987

12. Ethier SP, Kudla A, Cundiff KC: The influence of hormone and growth factor interactions on the proliferative potential of normal rat mammary epithelial cells in vitro. J Cell Physiol 132: 161-167, 1987

13. Butler WB: Preparing nuclei from cells in monolayer cultur- es suitable for counting and for following synchronized cells through the cell cycle. Anal Biochem 141: 70-73, 1984

14. Kovach JS, Mcgovern RM, Cassady JD, Swanson SK, Wold LE, Vogelstein B, Sommer SS: Direct sequencing from touch preparations of human carcinomas - analysis of p53 mutations in breast carcinomas. J Nat Cancer Inst 83: 10041009,1991

15. Ethier SP, Moorthy R, Dilts CA: Secretion of an epidermal growth factor-like growth factor by epidermal growth factor-independent rat mammary carcinoma cells. Cell Growth Diff 2: 593-602, 1991

16. Frye RA, Benz CC, Liu E: Detection of amplified oncogenes by differential polymerase chain reaction. Oncogene 4: 1153-1157, 1989

17. Neubauer A, Neubauer B, He M, Effert P, Iglehart D, Frye RA, Liu E: Analysis of gene amplification in archival tissue by differential polymerase chain reaction. Oncogene 7 : 1019-1025, 1992

18. Al-Kasspooles M, Moore JH, Orringer MB, Beer D: Amplification and over-expression of the EGFR and erbB-2 genes in human esophageal adenocarcinomas. Int J Cancer 54:1-7, 1993

19. Ethier SP: Serum-free culture conditions for the growth of normal rat mammary epithelial cells in primary culture. In Vitro: Cell Dev Biol 22: 485-490, 1986

20. Petersen OW, van Deurs B, Nielsen KV, Madsen MW, Laursen I, Balslev I, Briand P: Differential tumorigenicity of two autologous human breast carcinoma cell lines, HMT-3909S1 and HMT-3909S8, established in serum-free medium. Cancer Res 50: 1257-1270, 1990

21. Schlessinger $\mathrm{J}$ : Allosteric regulation of the epidermal growth factor receptor kinase. J Cell Biol 103: 2067-2072, 1986

22. Yarden Y, Schlessinger J: Self-phosphorylation of epidermal growth factor receptor: Evidence for a model of intermolecular allosteric activation. Biochemistry 26: 1434-1442, 1987

23. Gill GN, Lazar CS: Increased phosphotyrosine content and inhibition of proliferation in EGF-treated A431 cells. Nature 293: 305-307, 1981

24. Wildenhain $\mathrm{Y}$, Pawson $\mathrm{T}$, Blackstein ME, Andrulis IL: p185neu is phosphorylated on tyrosine in human primary breast tumors which overexpress neu/erbB-2. Oncogene 5: $879-883,1990$ 